Article

\title{
Response of Human Neutrophil Granulocytes to the Hyphae of the Emerging Fungal Pathogen Curoularia lunata
}

\author{
Eszter Judit Tóth ${ }^{1,2}$, Mónika Varga ${ }^{2}$, Miklós Takó ${ }^{2}{ }^{\circledR}$, Mónika Homa ${ }^{1}$, Olivér Jáger ${ }^{1,2}$, \\ Edit Hermesz ${ }^{3}\left(\mathbb{D}\right.$, Hajnalka Orvos ${ }^{4}$, Gábor Nagy ${ }^{1,2} \mathbb{D}$, Csaba Vágvölgyi ${ }^{2} \mathbb{D}$ and \\ Tamás Papp 1,2,*DiD \\ 1 MTA-SZTE Fungal Pathogenicity Mechanisms Research Group, Hungarian Academy of \\ Sciences-University of Szeged, 6726 Szeged, Hungary; forimistio@gmail.com (E.J.T.); \\ homamoni@gmail.com (M.H.); jager.oliver.biology@gmail.com (O.J.); nagygab86@gmail.com (G.N.) \\ 2 Department of Microbiology, Faculty of Science and Informatics, University of Szeged, 6726 Szeged, \\ Hungary; varga.j.monika@gmail.com (M.V.); tako78@bio.u-szeged.hu (M.T.); csaba@bio.u-szeged.hu (C.V.) \\ 3 Department of Biochemistry and Molecular Biology, Faculty of Science and Informatics, University of \\ Szeged, 6726 Szeged, Hungary; hermeszedit@gmail.com \\ 4 Department of Obstetrics and Gynecology, Faculty of Medicine, University of Szeged, 6725 Szeged, Hungary; \\ orvosh@obgyn.szote.u-szeged.hu \\ * Correspondence: pappt@bio.u-szeged.hu
}

Received: 6 March 2020; Accepted: 20 March 2020; Published: 21 March 2020

check for updates

\begin{abstract}
Curvularia lunata is an ascomycete filamentous fungus causing local and invasive phaeohyphomycoses in both immunocompromised and immunocompetent patients. Neutrophils are crucial participants of the first line host defense against fungal infections. They migrate to the infected site and eliminate the infectious agents by various mechanisms including phagocytoses, oxidative damage, or formation of neutrophil extracellular trap (NET). Neutropenia may be a risk factor for phaeohyphomycoses, and restoration of the neutrophil function can improve the outcome of the infection. In the present study, interaction of primary human neutrophil granulocytes with the hyphae C. lunata was examined and compared to that with the well characterized filamentous fungal pathogen Aspergillus fumigatus. Neutrophils could recognize the serum opsonized hyphae of $C$. lunata and attach to them. Myeloperoxidase release was also activated by a soluble factor present in the culture supernatant of the fungus. Induction of the oxidative burst was found to depend on serum opsonization of the hyphae. Although extracellular hydrogen peroxide production was induced, the fungus efficiently blocked the oxidative burst by acidifying the reaction environment. This blockage also affected the NET forming ability of the neutrophils.
\end{abstract}

Keywords: Curvularia; phaeohyphomycosis; neutrophil extracellular trap; oxidative burst; myeloperoxidase; hydrogen peroxide; acidification

\section{Introduction}

Curvularia is an ascomycete fungal genus, which mainly includes saprotrophic and plant pathogenic species. However, it is also considered as one of the most relevant filamentous fungal group involved in local and invasive phaeohyphomycoses, i.e., human infections caused by dematiaceous fungi [1-4]. Curvularia infections can manifest as mycotic keratitis [5], cutaneous and subcutaneous mycosis [6], onychomycosis [7], peritonitis [8], and allergic sinusitis [8,9]. Deep infections frequently affect the central nervous system [8-10]. Development of disseminated mycoses has been reported in both immunocompromised and immunocompetent patients [11-14]. Within the genus, C. lunata is among 
the species most frequently identified from clinical samples $[5,15]$. Despite their abovementioned role as the causative agents of phaeohyphomycoses, there are only very limited information available about the immunological aspects and the pathomechanisms of Curvularia infections [16].

Immunosuppression and immunodeficiencies result in predisposition to opportunistic fungal infections [17], including those of Curvularia species [4]. Action of monocytes and macrophages phagocyting the conidia and neutrophils causing hyphal damage has a key role in the prevention of invasive mycotic infections $[18,19]$. Neutrophils are among the first immune cells, which migrate to the infected site and they eliminate the microbes by various mechanisms involving phagocytoses, formation of neutrophil extracellular trap (NET) or release of oxidative molecules (such as hydrogen peroxide or hydroxyl radicals), enzymes or antimicrobial peptides [20,21]. Action of neutrophil granulocytes against Aspergillus is a well-studied field of host-fungal pathogen interactions [17,22,23] but little is known about their role in the defense to Curvularia species and other dematiaceous molds. Neutropenia was found to be associated with high risk of death in phaeohyphomycosis, while recovery from neutropenia improved the chance of the survival [24].

In a recent study, we examined the interaction of $C$. lunata with human monocytes and compared it to that of A. fumigatus and other Curvularia species [16]. In that study, monocytes attached to the hyphae of $C$. lunata produced interleukin (IL)- 8 in an elevated level. The primary role of this cytokine is to recruit neutrophils to the site of infection [25]. Here, we report the interaction of C. lunata with human neutrophil granulocytes, which represent another key component of the first line defense in the elimination of the fungal pathogens.

\section{Results}

\subsection{Activation of the Neutrophils by the C. lunata Hyphae}

The culture supernatant of C. lunata with the hyphae and the serum opsonized hyphae induced the myeloperoxidase (MPO) release of the neutrophils (Figure 1). If the culture supernatant was changed to modified Krebs-Ringer phosphate glucose (mKRPG) buffer over the hyphae, MPO release did not increase compared to the untreated neutrophils. Presence of the A. fumigatus hyphae induced significant MPO release only after serum opsonization, while the culture supernatant of the germinated conidia could not activate the neutrophils.

\subsection{Generation of Hydrogen Peroxide $\left(\mathrm{H}_{2} \mathrm{O}_{2}\right)$}

Both C. lunata and A. fumigatus hyphae induced the $\mathrm{H}_{2} \mathrm{O}_{2}$ release only after opsonization (Figure 2). Interestingly, the released $\mathrm{H}_{2} \mathrm{O}_{2}$ almost completely disappeared at the 60th min of the interaction with C. lunata, while its level proved to be more or less constant in the case of A. fumigatus. Without the fungi, $\mathrm{H}_{2} \mathrm{O}_{2}$ release of the neutrophil cell could not be detected.

\subsection{Detection of Extracellular Melanin}

As C. lunata hyphae can produce dihydroxynaphthalene (DHN)-type melanin, which may affect the oxidative damage by the neutrophils, melanin production during the interaction was tested. Acidification causes precipitation of the melanin pigment. However, by acidifying the supernatant of the interaction, no precipitation was formed, and no visible residue left on the polytetrafluoroethylene (PTFE) membrane. Acidification and filtering of the culture media from 7 days long cultivations in mKRPG showed the same result. 


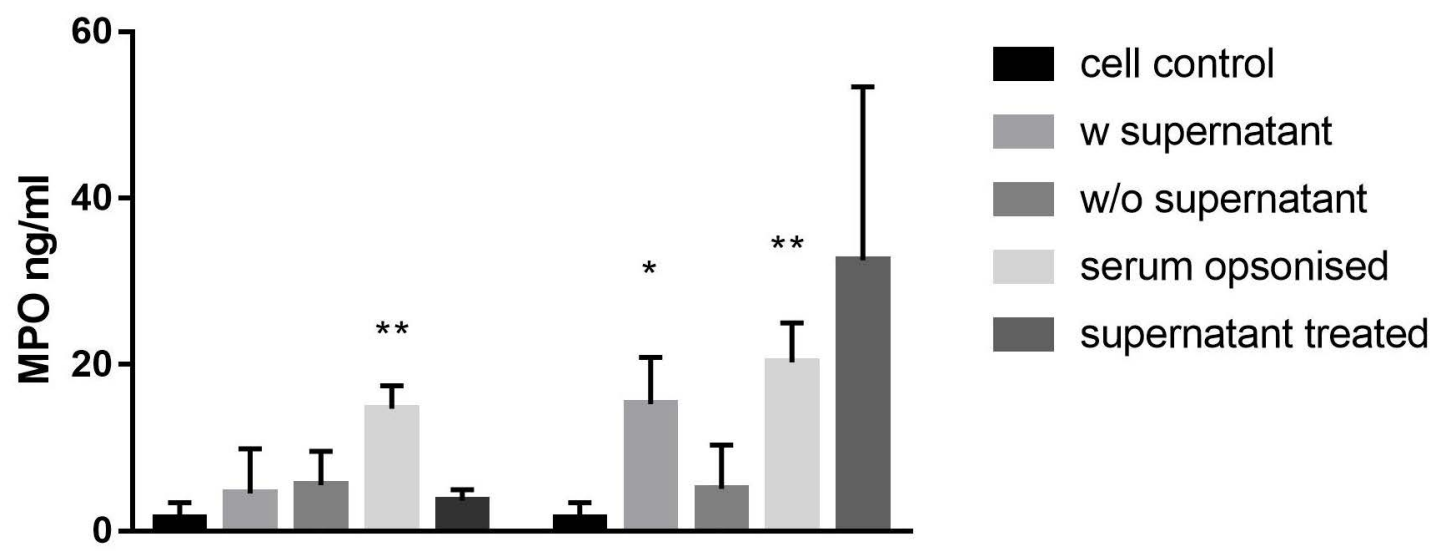

\section{A. fumigatus C. lunata}

Figure 1. Neutrophil granulocytes are activated by serum opsonized C. lunata and by the culture supernatant of the hyphae. Myeloperoxidase (MPO) release of neutrophil granulocytes was measured after $60 \mathrm{~min}$ of interaction with $A$. fumigatus and C. lunata. Cell control: untreated neutrophils; w supernatant: neutrophils were added directly to the germinated conidia; w/o supernatant: germinated conidia were washed with fresh mKRPG before addition of neutrophils; serum opsonized: young hyphae were serum opsonized before addition of neutrophils; supernatant treated: cell free culture supernatant of the germinated conidia was added to the neutrophils. Error bars represent standard deviations calculated from three biological parallels. Significance was calculated with multiple t-test compared to the cell control using the GraphPad Prism 7 software, FDR $(\mathrm{Q}=10 \%),{ }^{*} p<0.05 * * p<0.0001$.

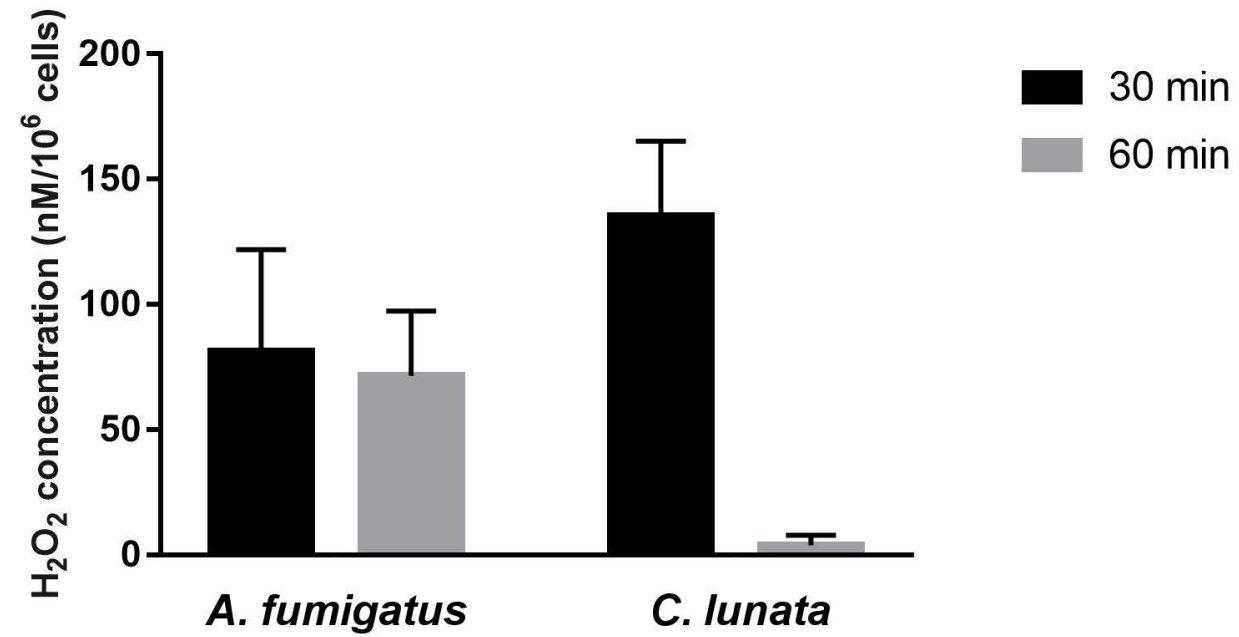

Figure 2. The amount of $\mathrm{H}_{2} \mathrm{O}_{2}$ decreases after 60 min of interaction with C. lunata. $\mathrm{H}_{2} \mathrm{O}_{2}$ concentration was measured after 30 and $60 \mathrm{~min}$ of interaction with the serum opsonized hyphae of $A$. fumigatus and C. lunata and it was normalized to $10^{6}$ neutrophils. Error bars represent standard deviations calculated from three biological parallels.

\subsection{NET Formation in the Presence of the Hyphae}

Serum opsonized A. fumigatus hyphae induced the NET formation, as it was published previously [17] (Figure 3a). In contrasts, NET formation was not observed in the presence of the C. lunata hyphae (Figure 3b). 


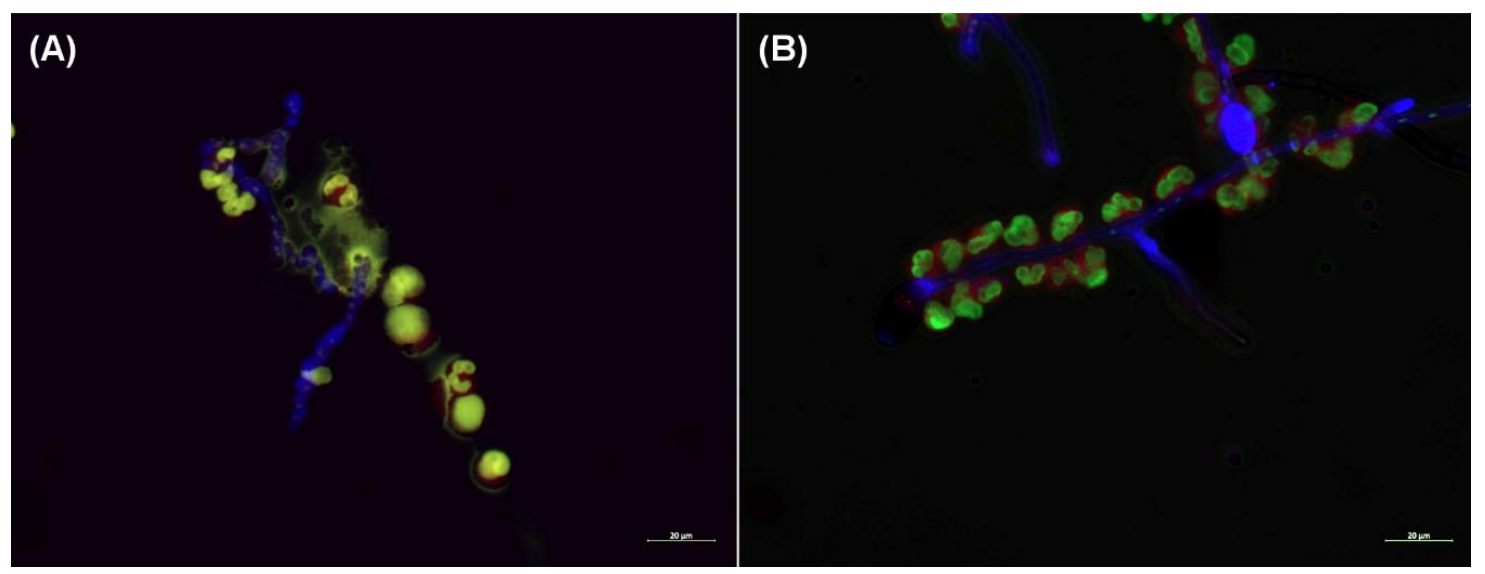

Figure 3. Neutrophil extracellular trap (NET) formation is missing when neutrophils are confronted with the hyphae of $C$. lunata. Fluorescent microscopy was performed about after $3 \mathrm{~h}$ of interaction of serum opsonized A. fumigatus (A) and C. lunata (B) with neutrophil granulocytes. Hyphae and conidia were labeled with Calcofluor white (blue); neutrophil's cell membrane was stained with CellMask Deep Red Plasma Membrane Stain (red) and the DNA was stained with SYTOX Green (green). NET formation was detected in the interaction with A. fumigatus but only gathering of the cells to the hyphae could be observed in case of C. lunata.

It was even not induced if $\mathrm{H}_{2} \mathrm{O}_{2}$ was added to the interactions. Seemingly, neutrophils recognized the serum opsonized hyphae and attached to it, but the lobular structure of the nuclei remained intact and no chromosome decondensation was observed. After $3 \mathrm{~h}$ of co-incubation with the neutrophils, the $17 \%$ and $33 \%$ of the nuclear areas of $A$. fumigatus indicated decondensation and NET formation, respectively (Figure 4). At the same time, $100 \%$ of the nuclei remained condensed in case of C. lunata. Without serum opsonization, neutrophils did not gather around the hyphae of both fungi.

(a)

\section{Aspergillus fumigatus}

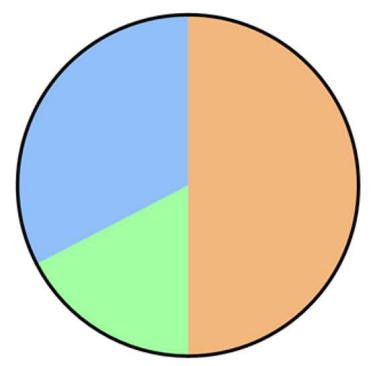

(b)

\section{Curvularia lunata}

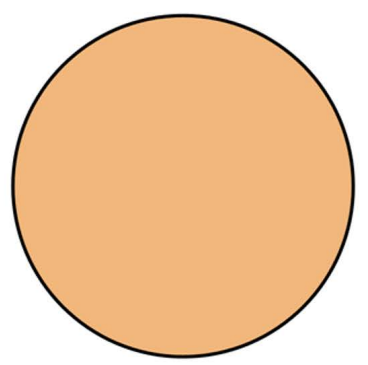

Figure 4. Ratio of the nuclear areas measured after $3 \mathrm{~h}$ of interaction of serum opsonized A. fumigatus (a) and C. lunata (b) with neutrophil granulocytes. Nuclear areas of $\leq 50 \mu \mathrm{m}^{2}$ were considered as condensed nuclei, those which were between 50 and $90 \mu \mathrm{m}^{2}$, were regarded as decondensed nuclei, while those measured to be $\geq 90 \mu \mathrm{m}^{2}$ indicated NET formations.

\subsection{Extracellular $p H$ of the Neutrophil-Fungus Interaction}

Infection of the neutrophils with $A$. fumigatus did not change significantly the extracellular $\mathrm{pH}$ compared to that of the uninfected cells at the tested timepoints (Figure 5a). However, serum opsonized hyphae of $\mathrm{C}$. lunata decreased the $\mathrm{pH}$ of the interaction environment even after $60 \mathrm{~min}$ and this decrease proved to be significant after $3 \mathrm{~h}$ of interaction (Figure $5 \mathrm{~b}$ ). 
(A)

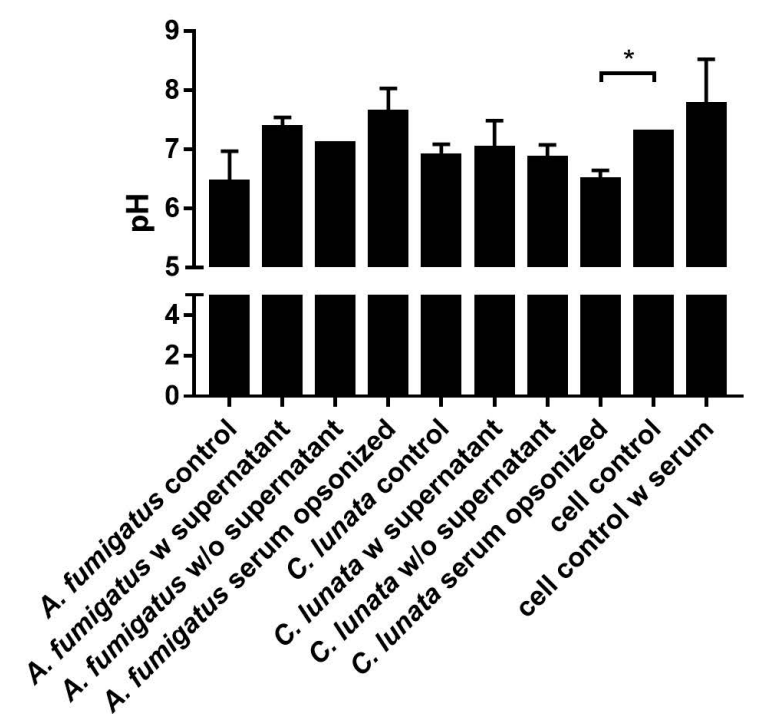

(B)

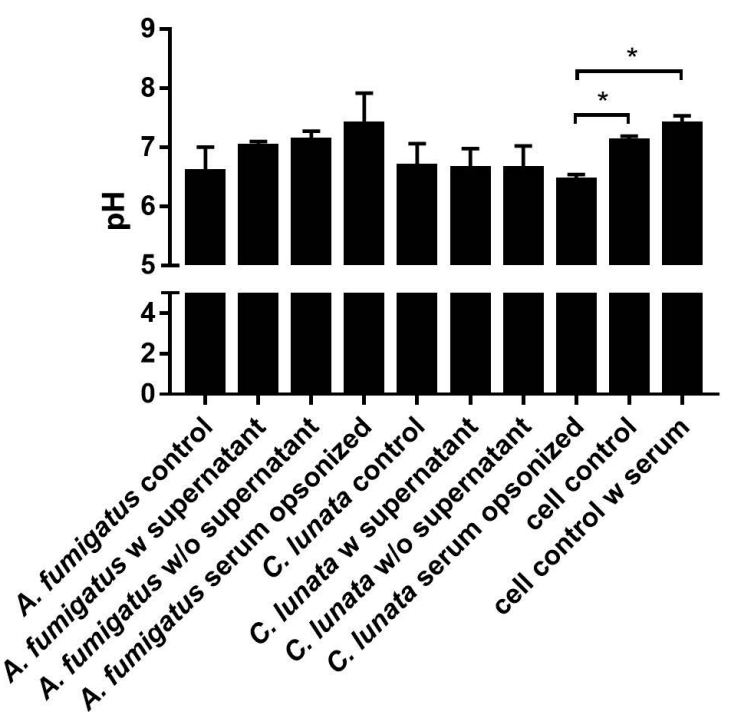

Figure 5. Extracellular $\mathrm{pH}$ of the environment after $60 \mathrm{~min}(\mathbf{A})$ and $3 \mathrm{~h}(\mathbf{B})$ of interaction with A. fumigatus and C. lunata. Addition of serum alkalifies the media; significance of serum opsonization conditions were calculated compared to the untreated neutrophils with and without serum as well. Control: untreated hyphae or neutrophils; w supernatant: neutrophils were added directly to the germinated conidia; w/o supernatant: germinated conidia were washed with fresh modified Krebs-Ringer phosphate glucose (mKRPG) buffer before addition of neutrophils; serum opsonized: young hyphae were serum opsonized before addition of neutrophils. Error bars represent standard deviations calculated form three biological parallels. Multiple t-test was used in GraphPad Prism 7 software, FDR (Q $=10 \%),{ }^{*} p<0.05$.

\subsection{Killing Efficiency of the Neutrophil Granulocytes}

While the neutrophils could effectively kill $A$. fumigatus in case of serum opsonization, viability of C. lunata did not decreased after $3 \mathrm{~h}$ of interaction under the examined conditions (Figure 6).

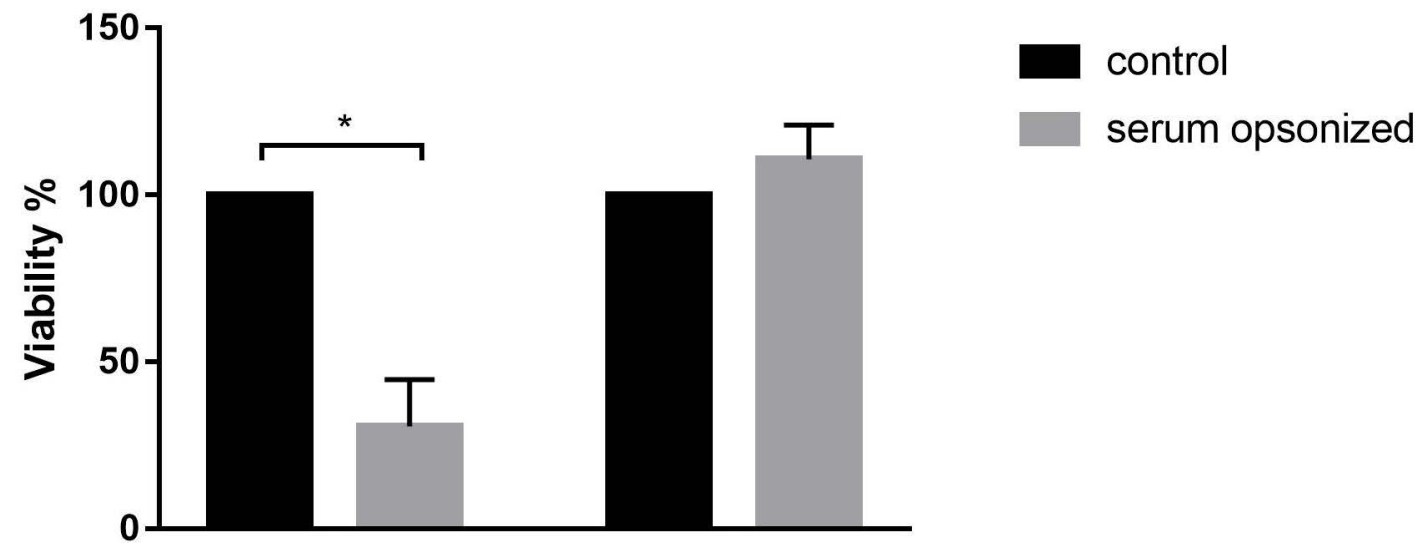
A. fumigatus
C. Iunata

Figure 6. Viability of C. lunata is not affected by 3 h-long interaction with neutrophils. Neutrophils were added to the serum opsonized hyphae. As a control, fungal strains were cultivated under the same conditions without immune cells. Viability is expressed as the percentage normalized to the control conditions. Error bars represent standard deviations calculated from three biological parallels. Significance was calculated with multiple t-test with False Discovery Rate (FDR) $(\mathrm{Q}=10 \%)$ in the GraphPad Prism 7 software, ${ }^{*} p<0.05$. 


\subsection{Viability of the Neutrophils in the Presence of the Fungal Hyphae}

At 60 min post-inoculation, significant death of the neutrophils was detected only in the presence of serum opsonized hyphae. C. lunata and A. fumigatus caused a cell death of $68 \%$ and $26 \%$ compared to the control, respectively.

\section{Discussion}

Neutrophils are key components of the host defense against fungal pathogens and neutropenia or inadequate neutrophilic response generally are considered as risk factors of opportunistic fungal infections. Therefore, the interaction of neutrophil granulocytes with opportunistic human pathogenic fungi is an intensively researched field [26]. In this respect, the most studied filamentous fungus is $A$. fumigatus [27]. Patients having chronic granulomatous disease (CGD), which is caused by a deficiency in the NADPH-oxidase system of phagocytes, making them unable to produce reactive oxygen species, are at high risk having invasive aspergillosis (IA) or other fungal infection. CGD also affects the NET forming capacity of neutrophils $[17,28]$. Disseminated phaeohyphomycoses including those caused by Curvularia spp. also occur with a higher prevalence in immunosuppressed patients, in which case, the survival rate was found to be higher when the patient recovered from neutropenia (24).

It is known that neutrophils recognize the A. fumigatus hyphae only after serum opsonization, and efficient killing mechanisms are then activated [17]. Consistently to this, activation of the neutrophils in the presence of the A. fumigatus hyphae could be observed only after opsonization. Opsonization of the $C$. lunata hyphae also led to the MPO release of the neutrophils indicating that the recognition may be similar to that of $A$. fumigatus. The fact that we could detect release of MPO when the supernatant of the hyphae was not removed before the infection or even only the supernatant was added to the neutrophil cells suggests that neutrophils could also recognize a soluble factor produced by C. lunata.

MPO forms a complex with the $\mathrm{H}_{2} \mathrm{O}_{2}$ produced during respiratory burst, which is responsible for the oxidation of halides forming hypohalous acids like hypochlorous acid $(\mathrm{HOCl})[29,30]$. NADPH oxidase of neutrophils produce high amount of superoxide $\left(\mathrm{O}_{2}{ }^{-}\right)$, which is converted into $\mathrm{H}_{2} \mathrm{O}_{2}$ by superoxide dismutase or by a spontaneous reaction [20]. By measuring the amount of $\mathrm{H}_{2} \mathrm{O}_{2}$ produced by the neutrophils in response to fungi, we observed that oxidative burst was activated only in the presence of the opsonized hyphae of both fungi. However, while the $\mathrm{H}_{2} \mathrm{O}_{2}$ level was quite constant in case of $A$. fumigatus, it reduced radically in the presence of $C$. lunata, indicating a potent antioxidant activity for the latter fungus.

C. lunata produces DHN-type melanin. Antioxidant capacity of melanin is well documented [31]. Moreover, the protective effect of melanin was proven against $\mathrm{H}_{2} \mathrm{O}_{2}$ and $\mathrm{HOCl}$ in the case of $A$. nidulans [32]. However, as the presence of released melanin was not detected in the interaction environment, it can be suggested that the drop of the $\mathrm{H}_{2} \mathrm{O}_{2}$ level was not the consequence of the antioxidant activity of this pigment in our study.

Large microbes and fungal hyphae trigger extracellular reactive oxygen species (ROS) release, which leads to recruiting further neutrophils and NET formation [33]. Interestingly, we detected $\mathrm{H}_{2} \mathrm{O}_{2}$ production in not all those cases when activation of neutrophils was seen. MPO release induced by the supernatant of the hyphae did not result in $\mathrm{H}_{2} \mathrm{O}_{2}$ production. MPO has important roles in the proinflammatory regulation. In a non-enzymatic way, it activates further neutrophils via an autocrine signaling pathway [34], mediates the recruitment of other leukocytes binding to their CD11b/CD18 receptors [35], and induces the IL-6 and IL-8 production of endothelial cells [36]. It is possible that the MPO functions as a regulating molecule when cells are activated by the soluble factor of C. lunata.

NET formation was observed in the presence of opsonized A. fumigatus but not in case of $C$. lunata, although neutrophils attached to the hyphae. NET formation is mainly regulated by the presence of ROS [37]. It is not clear if there is a specific ROS regulating the process. According to Nishinaka [38], singlet oxygen is the main inducer of NET production, but there are also data contradicting this hypothesis [39,40]. In parallel with the lack of NET formation, an acidification of the reaction environment was observed in the case of $C$. lunata. It was recently reported that acidification 
of the environment can inhibit the NET formation of neutrophils via the impeding of ROS production, but addition of $\mathrm{H}_{2} \mathrm{O}_{2}$ was enough to induce NET appearance [41]. Considering that $\mathrm{H}_{2} \mathrm{O}_{2}$ almost disappeared and the extracellular $\mathrm{pH}$ was found around 6.5 during the interaction with $\mathrm{C}$. lunata, this can explain the lack of NET formation in response to this strain.

Viability of fungal strains was determined after three hours of interaction. While neutrophils were able to kill $A$. fumigatus efficiently, viability of $C$. lunata did not decrease after the interaction. This data is in line with our other results, suggesting that $C$. lunata can efficiently block the neutrophil functions. Cell death of neutrophils was also measured after the interaction. In the presence of $C$. lunata, neutrophils were more viable than those in the interaction with A. fumigatus. This result is in agreement with the observation that acidification of the reaction environment prolongs the lifespan of neutrophils [41] and supports the possible role of acidification in the protection of the fungus against neutrophil effector functions.

In a previous study, we found that THP-1 monocytes responded only to the hyphae of C. lunata by attaching to them and producing elevated levels of the anti-inflammatory cytokine IL-10 [16]. Induction of IL-10 together with the observation that monocytes could not reduce the viability of the fungus correlates well to the fact that $C$. lunata frequently cause chronic infections even in immunocompetent persons [8]. Neutrophils also could not decrease the fungal viability and their NET formation was blocked by the hyphae. This efficient evasion of the monocytic and the neutrophil attacks may contribute in the ability of this fungus to cause disseminated infections even in immunocompetent patients $[8,11,12,14]$.

\section{Materials and Methods}

\subsection{Fungal Strains, Culture Conditions, and Inoculum Preparation}

The fungal strains, Curvularia lunata SZMC 23759 and Aspergillus fumigatus SZMC 23245 isolated from human eye infections were used (SZMC, Szeged Microbiology Collection, Szeged, Hungary; http://www.wfcc.info/ccinfo/collection/by_id/987). To harvest the conidia, fungi were grown on rice flour agar ( $1 \%$ rice flour, $0.2 \%$ yeast extract, $1.5 \%$ agar) at room temperature. Conidia were washed from 7 days old colonies with modified Krebs-Ringer phosphate glucose (mKRPG) buffer (145 mM $\mathrm{NaCl}, 5.7 \mathrm{mM} \mathrm{Na}_{2} \mathrm{HPO}_{4}, 4.86 \mathrm{mM} \mathrm{KCl}, 5.5 \mathrm{mM}$ glucose, $\mathrm{pH} 7.35$ ) and the spore suspensions were filtered through a Millipore filter with a pore size of $45 \mu \mathrm{m}$ (Merck, Burlington, USA) to eliminate the hyphal debris.

\subsection{Isolation of Human Neutrophil Granulocytes and Serum}

Human neutrophils were isolated from heparinized venous blood of healthy donors $(n=6)$ with dextran (Sigma-Aldrich, St. Louis, MI, USA) sedimentation followed by centrifugation over Ficoll-Paque PLUS (GE Healthcare, Chicago, IL, USA) and hypotonic lysis of erythrocytes [42]. Isolation was performed at room temperature. After isolation, the cells were resuspended in mKRPG. Viability and purity of the cells were checked with trypan blue (Sigma-Aldrich, St. Louis, MI, USA) [43] and Wright staining (Sigma-Aldrich, St. Louis, MI, USA) [44,45], respectively. Serum was isolated from venous blood of the same donors taken into serum separation blood collection tubes (BD Vacutainer, Becton Dickinson, Franklin Lakes, NJ, USA). Then, coagulation tubes were centrifuged at $1200 \mathrm{rpm}$ for $15 \mathrm{~min}$ at room temperature and the serum was collected.

\subsection{Interaction of the Neutrophils and the Hyphae}

To produce young hyphae, $2 \times 10^{4}$ conidia were inoculated in $100 \mu \mathrm{L}$ mKRPG in a 96-well plate (Sarstedt, Nümbrecht, Germany) and incubated at $37^{\circ} \mathrm{C}$. Considering that the time of the germ tube formation from the conidia is different for Aspergillus and Curvularia, the incubation time was set to 4 and $8 \mathrm{~h}$ in case of C. lunata and A. fumigatus, respectively, to obtain the same length of hyphae for both strains. The isolated neutrophils were added to the germinated conidia in an effector:target (E:T) 
ratio of 5:1 in $100 \mu \mathrm{L}$ mKRPG in a 96-well plate. Interactions were examined after 30, 60, or $180 \mathrm{~min}$ under three conditions: (a) neutrophils were added directly to the germinated conidia; (b) neutrophils were added to germinated conidia previously washed with fresh mKRPG buffer; and (c) neutrophils were added to the germinated conidia, which was previously serum opsonized with $10 \%$ serum of the corresponding donor in the last hour of germination. For detection of neutrophil activation, a fourth condition was also examined, in which the cell free supernatant of the germinated conidia was added to the neutrophils. Final volume of the interactions was $200 \mu \mathrm{L}$.

To detect possible NET formation, $7 \times 10^{4}$ conidia were germinated in CELLview dishes (Greiner Bio-One, Mosonmagyaróvár, Hungary) in $400 \mu \mathrm{L}$ mKRPG buffer and neutrophils were added to them in an E:T ratio of 5:1. Final volume of the reaction was $800 \mu \mathrm{L}$.

\subsection{Detection of Neutrophil Activation}

To measure the activation of neutrophils, the MPO activity was determined using 3,3',5,5' -tetramethylbenzidine (TMB; Sigma-Aldrich, St. Louis, MI, USA) at the 30th and 60th min of the co-incubation according to the method of Suzuki et al. [46]. To exclude other peroxidase activities from the measurement, the MPO inhibitor 4-aminobenzoic hydrazide (ABH) was added to a parallel measurement in a concentration of $1 \mathrm{mM}$. MPO activity of the untreated neutrophils was considered as a control. The standard curve was generated based on the reaction of Recombinant Human Myeloperoxidase Protein (R\&D Systems, Minneapolis, MN, USA) using 4-parametric logistic regression.

\subsection{Measurement of the $\mathrm{H}_{2} \mathrm{O}_{2}$ Release of Neutrophils}

Release of $\mathrm{H}_{2} \mathrm{O}_{2}$ was measured with the Amplex Red Hydrogen Peroxide/Peroxidase Assay Kit (Invitrogen, Carlsbad, CA, USA) 30 and $60 \mathrm{~min}$ after the infection according to the manufacturer's recommendation.

\subsection{Detection of Extracellular Melanin Release}

Extracellular melanin release of C. lunata was analyzed during the fungi-neutrophil granulocyte interaction, as well as after the cultivation of the fungi in mKRPG for 7 days. Conditions of the interaction were the same as described in the Section 4.3. The supernatant from the interaction was centrifuged at $6000 \mathrm{rpm}$ for $10 \mathrm{~min}$, while the $\mathrm{mKRPG}$ from the cultivation was filtered through gauze. The flowthrough was acidified to $\mathrm{pH} 2.0$ with addition of $\mathrm{HCl}$ and the resulting precipitate was filtered on a $0.2 \mu \mathrm{m}$ PTFE membrane [47].

\subsection{Visualization of NET Formation}

NET formation was analyzed after $3 \mathrm{~h}$ of co-incubation (the E:T ratio was 5:1). Samples were fixed with $1 \%$ formaldehyde solution for $15 \mathrm{~min}$.

To measure the chromosome decondensation and visualize the netosis, staining solutions were prepared in $10 \mathrm{mM}$ sodium citrate buffer (pH 7.2). To stain the NET, $167 \mathrm{nM}$ SYTOX Green nucleic acid stain (Life Technologies, Carlsbad, CA, USA) was applied for $30 \mathrm{~min}$, while the fungal and the neutrophil cells were stained with $5 \mu \mathrm{g} / \mathrm{mL}$ Calcofluor white (Cyanamid, NJ, USA) for $15 \mathrm{~min}$ and a 0.5-fold solution of the CellMask Deep Red Plasma Membrane Stain (Thermo Scientific, Waltham, MA, USA) for $15 \mathrm{~min}$, respectively. Between the staining steps and after the whole process, samples were washed two times with $10 \mathrm{mM}$ sodium citrate buffer.

To induce NET formation by hydrogen peroxide $\left(\mathrm{H}_{2} \mathrm{O}_{2}\right)$, the latter was added to the interactions after 0,1 , and $2 \mathrm{~h}$ of co-incubation in a final concentration of $30 \mu \mathrm{M}$ [41].

Microscopic examinations were carried out with an Axio Observer 7 (Zeiss, Oberkochen, Germany) fluorescent inverted microscope. 


\subsection{Measurement of Chromosome Decondensation}

Chromosome decondensation was analyzed on the pictures of samples stained with SYTOX green, Calcofluor white, and CellMask Deep Red and taken by fluorescent microscopy. For each sample, at least 35 cells were analyzed. SYTOX Green positive area was measured with ImageJ for each cell as described before [48]. Nuclear areas found to be $\leq 50 \mu \mathrm{m}^{2}$ were considered as condensed nuclei, those, which were between 50 and $90 \mu^{2}$, were regarded as decondensed nuclei, while those measured to be $\geq 90 \mu \mathrm{m}^{2}$ indicated NET formations.

\subsection{Measurement of Extracellular $\mathrm{pH}$}

Extracellular $\mathrm{pH}$ was determined from the cell-free supernatant of the interaction at $60 \mathrm{~min}$ and 3 $\mathrm{h}$ post-inoculation with litmus solution (CPAChem, Stara Zagora, Bulgaria). Calibration curve was generated from a $\mathrm{pH}$ scale of mKRPG with the linear regression model. To $100 \mu \mathrm{L}$ of supernatant or mKRPG $5 \mu \mathrm{L}$ of $2 \%$ litmus solution was added in a 96-well plate. Absorption was measured at $580 \mathrm{~nm}$ with a SPECTROstar Nano Microplate Reader (BMG Labtech, Ortenberg, Germany).

\subsection{Viability Assay for the Hyphae}

To measure the hyphal damage after incubation with the neutrophils, a colorimetric assay using 3-(4,5-dimethylthiazol-2-yl)-2,5-diphenyltetrazolium bromide (MTT; Sigma-Aldrich, St. Louis, MI, USA) was performed in 96-well plates [49]. After $3 \mathrm{~h}$ of coincubation, neutrophils were lysed with $0.5 \%$ sodium deoxycholate (Sigma-Aldrich) and the wells were washed three times with PBS. Two hundred $\mu \mathrm{L}$ of mKRPG buffer supplemented with $0.5 \%$ MTT was added to the samples and the plates were incubated at $37^{\circ} \mathrm{C}$ for $3 \mathrm{~h}$. After removing the supernatant, wells were washed two times with PBS and stored overnight at $-20{ }^{\circ} \mathrm{C}$. Before detection, $200 \mu \mathrm{L}$ acidic isopropanol (95\% isopropanol and 5\% $1 \mathrm{~N} \mathrm{HCl}$ ) was added into the wells and the plates were incubated until the blue color dissolved from the hyphae. Absorbance of the supernatant was measured at the wavelength of $550 \mathrm{~nm}$ using a spectrophotometer. Viability of the hyphae was calculated using the following formula, where $O D_{550}$ sample was the absorbance measured for the hyphae incubated with neutrophils and $O D_{550}$ control was the absorbance measured for the hyphae incubated without neutrophils: Viability $=\left(\frac{\text { OD550 sample }}{\text { OD550 control }}\right) \times 100$.

\subsection{Neutrophil Viability Assay}

Cell death of neutrophil granulocytes following 60-min co-incubation was measured by the LDH Cytotoxicity Detection Kit (Takara Bio, Shiga, Japan) according to the manufacturer's instructions. For the measurement of the lactate dehydrogenase (LDH) released into the medium due to the cell death, the cell free supernatant of the cultures was used in a 10-fold dilution. The cell culture supernatant incubated without the hyphae were used as the low control. For high control, neutrophils incubated without the hyphae were lysed with Triton X-100 in a final concentration of 1\%. From the data of the low and high controls, a calibration curve was presented, and viability was calculated from the equation of the line.

\subsection{Statistical Analysis}

All measurements were performed in three biological and two technical parallels. Significance was calculated with multiple t-test with False Discovery Rate (FDR) $(\mathrm{Q}=10 \%$ ) in the GraphPad Prism 7 software (GraphPad Software, San Diego, CA, USA).

\subsection{Ethics Statement}

Conforming to the principles outlined in the Declaration of Helsinki, and the healthy volunteers informed consent, blood was taken in the Department of Obstetrics and Gynecology at the University 
of Szeged, Hungary. The Ethics Committee of the Department of Obstetrics and Gynecology approved the study protocol (20/2016-SZTE).

\section{Conclusions}

Our results show that neutrophils are able to recognize the serum opsonized hyphae of C. lunata and can attach to them. They are also activated by a soluble factor produced by the fungus, although induction of oxidative burst is dependent on the presence of the opsonized hyphae. These results suggest the regulatory role of MPO in the immune response against C. lunata. Nevertheless, $\mathrm{H}_{2} \mathrm{O}_{2}$ is generated after the activation of the cells. However, oxidative burst seems to be blocked by the fungus after 60 min of interaction. This blockage also influences the NET formation of neutrophils, with which C. lunata can efficiently survive the neutrophil attack.

Author Contributions: Conceptualization, E.J.T. and T.P.; methodology, E.J.T., T.P. and T.M.; validation, E.J.T. and T.P.; formal analysis, E.J.T., T.P. and G.N.; investigation, E.J.T., M.V., M.H., O.J., C.V. and G.N.; resources, E.J.T., M.T., E.H. and H.O.; writing—original draft preparation, E.J.T. and T.P.; writing—-review and editing, T.P. and C.V.; supervision, T.P.; project administration, T.P., G.N. and M.H.; funding acquisition, T.P. and G.N. All authors have read and agreed to the published version of the manuscript.

Funding: This study was funded by the "Lendület" Grant of the Hungarian Academy of Sciences (LP2016-8/2016), the project NKFI K131796 and the FIKP program (TUDFO/4738-1/2019 ITM) of the Ministry of Human Capacities. MT was supported by the grants J. Bolyai Research Scholarship of the Hungarian Academy of Sciences and the UNKP-18-4 New National Excellence Program of the Ministry of Human Capacities. EJT was supported by the UNKP-18-3 New National Excellence Program of the Ministry of Human Capacities.

Acknowledgments: The authors would like to thank Katalin Szabó and Alexandra Hoffmann for their help in the preparation of the blood samples and the interaction studies.

Conflicts of Interest: The authors declare no conflict of interest.

\section{References}

1. Perfect, J.R.; Alexander, B.D.; Schell, W.A. Phaeohyphomycoses (Brown-Black Moulds). In Essentials of Clinical Mycology, 2nd ed.; Kauffman, C.A., Pappas, P.G., Sobel, J.D., Dismukes, W.E., Eds.; Springer: New York, NY, USA, 2011; pp. 305-317.

2. Paredes, K.; Capilla, J.; Sutton, D.A.; Mayayo, E.; Fothergill, A.W.; Guarro, J. Experimental treatment of Curvularia infection. Diagn. Microbiol. Infect. Dis. 2014, 79, 428-431. [CrossRef]

3. Krizsan, K.; Toth, E.; Nagy, L.G.; Galgoczy, L.; Manikandan, P.; Chandrasekaran, M.; Kadaikunnan, S.; Alharbi, N.S.; Vágvölgyi, C.; Papp, T. Molecular identification and antifungal susceptibility of Curvularia australiensis, C. hawaiiensis and C. spicifera isolated from human eye infections. Mycoses 2015, 58, 603-609. [CrossRef] [PubMed]

4. Revankar, S.G.; Baddley, J.W.; Chen, S.C.; Kauffman, C.A.; Slavin, M.; Vazquez, J.A.; Seas, C.; Morris, M.I.; Nguyen, M.H.; Shoham, S.; et al. A mycoses study group international prospective study of phaeohyphomycosis: An analysis of 99 proven/probable cases. Open Forum. Infect. Dis. 2017, 4, ofx200. [CrossRef] [PubMed]

5. Khan, I.D.; Makkar, A.; Malik, A.; Khan, S.; Mehdi, I.; Arif, S.; Aden, D.; Somayaji, P.; Roomi, K. Curvularia keratomycosis after cataract surgery. J. Arch. Milit. Med. 2017, 5, e57331.

6. Rasheeduddin, M.; Visalakshi, P. Cutaneous phaeohyphomycosis of foot web by Curvularia lunata. Glob. J. Med. Clin. Case Rep. 2017, 4, 074-075. [CrossRef]

7. Vineetha, M.; Palakkal, S.; Sobhanakumari, K.; Celine, M.I.; Letha, V. Verrucous onychomycosis caused by Curvularia in a patient with congenital pterygium. Indian J. Dermatol. 2016, 61, 701. [CrossRef] [PubMed]

8. Krizsán, K.; Papp, T.; Manikandan, P.; Shobana, S.; Chandrasekaran, M.; Vágvölgyi, C.; Kredics, L. Clinical importance of the genus Curvularia. In Medical Mycology: Current Trends and Future Prospects; Razzaghi-Abyaneh, M., Shams-Ghahfarokhi, M., Rai, M., Eds.; CRC Press: Boca Raton, FL, USA, 2015; pp. 147-204.

9. Cavanna, C.; Seminari, E.; Pusateri, A.; Mangione, F.; Lallitto, F.; Esposto, M.C.; Pagella, F. Allergic fungal rhinosinusitis due to Curvularia lunata. New Microbiol. 2014, 37, 241-245. 
10. Skovrlj, B.; Haghighi, M.; Smethurst, M.E.; Caridi, J.; Bederson, J.B. Curvularia abscess of the brainstem. World Neurosurg. 2014, 82, e9-e241. [CrossRef]

11. Revankar, S.G.; Patterson, J.E.; Sutton, D.A.; Pullen, R.; Rinaldi, M.G. Disseminated phaeohyphomycosis: Review of an emerging mycosis. Clin. Infect. Dis. 2002, 34, 467-476. [CrossRef]

12. Kobayashi, H.; Sano, A.; Aragane, N.; Fukuoka, M.; Tanaka, M.; Kawaura, F.; Fukuno, Y.; Matsuishi, E.; Hayashi, S. Disseminated infection by Bipolaris spicifera in an immunocompetent subject. Med. Mycol. 2008, 46, 361-365. [CrossRef]

13. Balla, A.; Pierson, J.; Hugh, J.; Wojewoda, C.; Gibson, P.; Greene, L. Disseminated cutaneous Curvularia infection in an immunocompromised host; diagnostic challenges and experience with voriconazole. J. Cutan. Pathol. 2016, 43, 383-387. [CrossRef] [PubMed]

14. Beckett, A.R.; Kahn, S.A.; Seay, R.; Lintner, A.C. Invasive Curvularia infections in burn patients: A case series. Surg. Infect. Case Rep. 2017, 2, 76-79. [CrossRef]

15. Shrivastava, A.; Tadepalli, K.; Goel, G.; Gupta, K.; Gupta, P.K. Melanized fungus as an epidural abscess: A diagnostic and therapeutic challenge. Med. Mycol. Case Rep. 2017, 16, 20-24. [CrossRef] [PubMed]

16. Tóth, E.J.; Boros, E.; Hoffmann, A.; Szebenyi, C.; Homa, M.; Nagy, G.; Vágvölgyi, C.; Nagy, I.; Papp, T. Interaction of THP-1 monocytes with conidia and hyphae of different Curvularia strains. Front. Immunol. 2017, 8, 1369. [CrossRef] [PubMed]

17. Gazendam, R.P.; van Hamme, J.L.; Tool, A.T.; Hoogenboezem, M.; van den Berg, J.M.; Prins, J.M.; Vitkov, L.; van de Veerdonk, F.L.; van den Berg, T.K.; Roos, D.; et al. Human neutrophils use different mechanisms to kill Aspergillus fumigatus conidia and hyphae: Evidence from Phagocyte Defects. J. Immunol. 2016, 196, 1272-1283. [CrossRef] [PubMed]

18. Brakhage, A.A.; Bruns, S.; Thywissen, A.; Zipfel, P.F.; Behnsen, J. Interaction of phagocytes with filamentous fungi. Curr. Opin. Microbiol. 2010, 13, 409-415. [CrossRef]

19. LeibundGut-Landmann, S.; Wuthrich, M.; Hohl, T.M. Immunity to fungi. Curr. Opin. Immunol. 2012, 24, 449-458. [CrossRef]

20. Babior, B.M.; Lambeth, J.D.; Nauseef, W. The neutrophil NADPH oxidase. Arch. Biochem. Biophys. 2002, 397, 342-344. [CrossRef]

21. Kolaczkowska, E.; Kubes, P. Neutrophil recruitment and function in health and inflammation. Nat. Rev. Immunol. 2013, 13, 159-175. [CrossRef]

22. Braem, S.G.; Rooijakkers, S.H.; van Kessel, K.P.; de Cock, H.; Wosten, H.A.; van Strijp, J.A.; Haas, P.J.A. Effective neutrophil phagocytosis of Aspergillus fumigatus is mediated by classical pathway complement activation. J. Innate Immun. 2015, 7, 364-374. [CrossRef]

23. Feldmesser, M. Role of neutrophils in invasive aspergillosis. Infect. Immun. 2006, 74, 6514-6516. [CrossRef] [PubMed]

24. Ben-Ami, R.; Lewis, R.E.; Raad, I.I.; Kontoyiannis, D.P. Phaeohyphomycosis in a tertiary care cancer center. Clin. Infect. Dis. 2009, 48, 1033-1041. [CrossRef] [PubMed]

25. Morton, C.O.; Bouzani, M.; Loeffler, J.; Rogers, T.R. Direct interaction studies between Aspergillus fumigatus and human immune cells; what have we learned about pathogenicity and host immunity? Front. Microbiol. 2012, 3, 413. [CrossRef] [PubMed]

26. Kobayashi, S.D.; Malachowa, N.; DeLeo, F.R. Influence of microbes on neutrophil life and death. Front. Cell Infect. Microbiol. 2017, 7, 159. [CrossRef]

27. Dagenais, T.R.; Keller, N.P. Pathogenesis of Aspergillus fumigatus in invasive aspergillosis. Clin. Microbiol. Rev. 2009, 22, 447-465. [CrossRef]

28. Bianchi, M.; Hakkim, A.; Brinkmann, V.; Siler, U.; Seger, R.A.; Zychlinsky, A.; Reichenbach, J. Restoration of NET formation by gene therapy in CGD controls aspergillosis. Blood 2009, 114, 2619-2622. [CrossRef]

29. Aratani, Y. Role of myeloperoxidase in the host defense against fungal infection. Nihon Ishinkin Gakkai Zasshi 2006, 47, 195-199. [CrossRef]

30. Klebanoff, S.J.; Kettle, A.J.; Rosen, H.; Winterbourn, C.C.; Nauseef, W.M. Myeloperoxidase: A front-line defender against phagocytosed microorganisms. J. Leukoc. Biol. 2013, 93, 185-198. [CrossRef]

31. Revankar, S.G.; Sutton, D.A. Melanized fungi in human disease. Clin. Microbiol. Rev. 2010, 23, 884-928. [CrossRef]

32. de Cassia, R.G.R.; Pombeiro-Sponchiado, S.R. Antioxidant activity of the melanin pigment extracted from Aspergillus nidulans. Biol. Pharm. Bull. 2005, 28, 1129-1131. 
33. Warnatsch, A.; Tsourouktsoglou, T.D.; Branzk, N.; Wang, Q.; Reincke, S.; Herbst, S.; Gutierrez, M.; Papayannopoulos, V. Reactive oxygen species localization programs inflammation to clear microbes of different size. Immunity 2017, 46, 421-432. [CrossRef] [PubMed]

34. Lau, D.; Mollnau, H.; Eiserich, J.P.; Freeman, B.A.; Daiber, A.; Gehling, U.M.; Brümmer, J.; Rudolph, V.; Münzel, T.; Heitzer, T.; et al. Myeloperoxidase mediates neutrophil activation by association with CD11b/CD18 integrins. Proc. Natl. Acad. Sci. USA 2005, 102, 431-436. [CrossRef] [PubMed]

35. Johansson, M.W.; Patarroyo, M.; Oberg, F.; Siegbahn, A.; Nilsson, K. Myeloperoxidase mediates cell adhesion via the alpha M beta 2 integrin (Mac-1; CD11b/CD18). J. Cell Sci. 1997, 110, 1133-1139. [PubMed]

36. Lefkowitz, D.L.; Roberts, E.; Grattendick, K.; Schwab, C.; Stuart, R.; Lincoln, J.; Allen, R.C.; Moguilevsky, N.; Bollen, A.; Lefkowitz, S.S. The endothelium and cytokine secretion: The role of peroxidases as immunoregulators. Cell Immunol. 2000, 202, 23-30. [CrossRef] [PubMed]

37. Fuchs, T.A.; Abed, U.; Goosmann, C.; Hurwitz, R.; Schulze, I.; Wahn, V.; Weinrauch, Y.; Brinkmann, V.; Zychlinsky, A. Novel cell death program leads to neutrophil extracellular traps. J. Cell Biol. 2007, 176, $231-241$. [CrossRef] [PubMed]

38. Nishinaka, Y.; Arai, T.; Adachi, S.; Takaori-Kondo, A.; Yamashita, K. Singlet oxygen is essential for neutrophil extracellular trap formation. Biochem. Biophys. Res. Commun. 2011, 413, 75-79. [CrossRef]

39. Palmer, L.J.; Cooper, P.R.; Ling, M.R.; Wright, H.J.; Huissoon, A.; Chapple, I.L. Hypochlorous acid regulates neutrophil extracellular trap release in humans. Clin. Exp. Immunol. 2012, 167, 261-268. [CrossRef]

40. Tripathi, J.K.; Sharma, A.; Sukumaran, P.; Sun, Y.; Mishra, B.B.; Singh, B.B.; Sharma, J. Oxidant sensor cation channel TRPM2 regulates neutrophil extracellular trap formation and protects against pneumoseptic bacterial infection. FASEB J. 2018, 32, 6848-6859. [CrossRef]

41. Behnen, M.; Moller, S.; Brozek, A.; Klinger, M.; Laskay, T. Extracellular acidification inhibits the ROS-dependent formation of neutrophil extracellular traps. Front. Immunol. 2017, 8, 184. [CrossRef]

42. Clark, R.A.; Nauseef, W.M. Isolation and functional analysis of neutrophils. Curr. Protoc. Immunol. $2001,7$. [CrossRef]

43. Strober, W. Trypan blue exclusion test of cell viability. Curr. Protoc. Immunol. 2015, 111, A3.B.1-A3.B.3. [CrossRef]

44. Conn, H.J. Biological Stains, 8th ed.; Williams and Wilkins: Baltimore, MD, USA, 1969; p. 498.

45. Clark, G. Staining Procedures, 3rd ed.; Williams and Wilkins: Baltimore, MD, USA, 1973; p. 418.

46. Suzuki, K.; Ota, H.; Sasagawa, S.; Sakatani, T.; Fujikura, T. Assay method for myeloperoxidase in human polymorphonuclear leukocytes. Anal. Biochem. 1983, 132, 345-352. [CrossRef]

47. Goncalves, R.C.; Lisboa, H.C.; Pombeiro-Sponchiado, S.R. Characterization of melanin pigment produced by Aspergillus nidulans. World J. Microbiol. Biotechnol. 2012, 28, 1467-1474. [CrossRef] [PubMed]

48. Gonzalez, A.S.; Bardoel, B.W.; Harbort, C.J.; Zychlinsky, A. Induction and quantification of neutrophil extracellular traps. Methods Mol. Biol. 2014, 1124, 307-318. [PubMed]

49. Levitz, S.M.; Diamond, R.D. A rapid colorimetric assay of fungal viability with the tetrazolium salt MTT. J. Infect. Dis. 1985, 152, 938-945. [CrossRef] [PubMed]

(C) 2020 by the authors. Licensee MDPI, Basel, Switzerland. This article is an open access article distributed under the terms and conditions of the Creative Commons Attribution (CC BY) license (http://creativecommons.org/licenses/by/4.0/). 